\title{
A price based automatic generation control using unscheduled interchange price signals in Indian electricity system
}

\author{
Saurabh Chanana*, Ashwani Kumar \\ Department of Electrical Engineering, National Institute of Technology Kurukshetra, INDIA \\ *Corresponding Author: e-mail: saurabh@nitkkr.ac.in, Tel +91-1744-233401, Fax.+91-1744-238050
}

\begin{abstract}
The Availability Based Tariff (ABT) mechanism has been introduced in Indian system mainly to ensure grid security and to deal with grid indiscipline prevailing in the system prior to its introduction. Unscheduled Interchange (UI) charge - one of the components of ABT, acts a mechanism for regulating the grid frequency. At the same time, this mechanism offers opportunity to participants to exchange as and when available surplus energy at a price determined by prevailing frequency conditions. Although the underlying principle on which UI mechanism of ABT operates is quite different from the conventional load frequency control mechanism, it can still be viewed as a price based secondary generation control mechanism. Presently, the generators are responding to price signals manually. In this paper, a model for price based automatic generation control is presented. A modified control scheme is proposed which will prevent unintended unscheduled interchanges among the participants. The proposed scheme is verified by simulating it on a model of isolated area system having four generators. It has been shown here that such control mechanism, if adopted by all generating stations, can improve the control of frequency and bring down the UI obligation of participants.
\end{abstract}

Keywords: Availability based tariff, generation control error, price based automatic generation control, unscheduled interchange price.

\section{Introduction}

India is one of the fastest growing economies in the world. Providing adequate electricity supply to fuel high growth rates has been one of the major challenges before the country. Despite of steady increase in power generation capacity over last few decades, demand growth has far outstripped supply growth. This has led to a continued energy shortage over the years. Even at present, the energy shortage and peak demand shortage are estimated to be $9.3 \%$ and 12.6\% respectively (CEA, 2009). The power deficit situation in the country was further aggravated by problems like fuel supply bottlenecks, high transmission and distribution losses, poor financial health of public utilities and a volatile electric grid with wide and rapid frequency fluctuations (Gupta and Sathaye, 2009; Yadav et al., 2005). Government of India has taken some path breaking initiatives during the last decade to overcome these problems. EA 2003 was enacted to introduce competition and efficiency in Indian power sector. The act envisages de-licensing of generation, unbundling of vertically integrated public utilities, introducing open access and allowing private participation in transmission and distribution sector (The Gazette of India, Extraordinary, 2003). Another important step has been introduction of ABT mechanism for bulk power transactions. The ABT mechanism has been introduced mainly to ensure grid security and deal with grid indiscipline prevailing in the system prior to its introduction (Bhushan, 2005).

Before the introduction of ABT scheme, grid operators in India faced a major problem in the form of grid indiscipline. A glaring symptom of which was wide and rapid fluctuations in grid frequency from below $48.0 \mathrm{~Hz}$ to above $52.0 \mathrm{~Hz}$ on daily basis. Abnormally low frequency during peak load hours was caused by inadequate generation capacity and attempts of meeting consumer loads in excess of available generation by public distribution utilities. High frequency during off-peak hours was the result of generation stations not backing down adequately when the consumer demand came down. The root cause of this problem was the then prevailing single part tariff structure for bulk power supply which disregarded the withdrawal pattern, deviation from schedule, system condition etc. 
ABT is a three-part tariff scheme. First part being a fixed component is linked to the availability of generating stations, second part is a variable component linked to the energy charges for scheduled interchange and third part is a frequency dependent component linked with the unscheduled interchange. In the given generation shortage scenario of Indian power system, the third component of ABT - the UI charge acts as a mechanism for regulating the grid frequency. At the same time, this mechanism offers opportunity to participants to exchange as and when available surplus energy at a price determined by prevailing frequency conditions (Bhushan et al., 2004). Although the underlying principle on which UI mechanism of ABT operates is quite different from the conventional load frequency control mechanism, it can still be viewed as a price based secondary generation control mechanism. Currently, the nature of this control is manual as generators see the price signal and respond to it by increasing or decreasing their output manually.

An automatic generation control scheme based in UI price has been presented by Tyagi and Srivastava (2004). This paper attempts further investigation on a price based automatic generation control (PBAGC) in Indian power system and how it can be modeled accurately. A modified control scheme is proposed which will prevent unintended unscheduled interchanges among the participants if PBAGC is introduced. It has been shown here that such mechanism, if adopted by all generating stations, can improve the control of frequency and bring the UI price down.

\section{Structure of Indian Power Sector}

Before we give details of the constituents of ABT scheme, it is necessary to explain the backdrop in which this scheme was introduced. The structure of ownership of generation and transmission facilities in India is based on the federal structure of the country. In each of the states in the region, most of the generation is owned by the State Electricity Boards (SEBs), which are vertically integrated utilities with generation, transmission and distribution under their control. Many of the SEBs are now unbundled into separate generation, transmission and distribution corporations. The Union Government (also called the Central Government) own generation utilities that supply bulk power to the SEBs based on allocations to the states made by the Union Government. These utilities are known as Central Generating Stations (CGSs) and currently supply around 34\% of the total generation to the system. Their share in generation capacity is projected to increase to $39 \%$ by 2012 .

The transmission grid is divided into five regional grids Northern, Western, Southern, Eastern and North-Eastern. All grids except Southern are now inter-connected via synchronous links. A Regional Load Dispatch Center (RLDC) in each of the region coordinates the daily scheduling process for dispatch of centrally generated power. Inter-regional exchanges are coordinated through National Load Dispatch Centre (IEGC, 2006). After collecting the availability of power from CGS for the next day (in 96 slots of 15 min each), RLDC allocates this power to respective SEBs as per their percentage share in CGS pool. SEBs then carry out an exercise to see how best they can meet the load of their consumers over the day, from their own generation stations along with their entitlement in CGS. They submit their requisitions to the RLDC, which then decides the dispatch schedule for CGS and withdrawal schedule for the SEBs.

\section{Availability Based Tariff}

To deal with the problems faced by grid operators a new tariff scheme: Availability Based Tariff was introduced in July 2002 . ABT comprises of three components: (a) Capacity Charge (b) Energy Charge (c) Unscheduled Inter-change (UI) Charge.

3.1 Capacity Charge: This component represents the fixed cost and is linked to the availability of the plant, i.e., its capability to deliver MWs on a day-by-day basis. The total amount payable to the generating company over a year towards the fixed cost would depend on the average availability of the plant over the year. In case the average actually achieved over the year is higher than the specified norm for plant availability, the generating company would get a higher payment. In case the average availability achieved is lower, the payment will be lower. Hence, the scheme is named Availability Based Tariff.

3.2 Energy Charge: This component of ABT comprises of the variable cost, i.e. the fuel cost of the power plant for generating energy as per given schedule for the day. Therefore, this energy charge is not according to the actual generation but only for scheduled generation.

3.3 Unscheduled Interchange Charge: In case there are deviations from schedule, this third component of ABT comes into picture. Deviations from schedule are determined in 15-minute time blocks through special metering. They are priced according to the system condition prevailing at that time. If the frequency is above $50 \mathrm{~Hz}$ (nominal frequency in Indian System), UI rate will be small and if it is below $50 \mathrm{~Hz}$, it will be high. As long as the actual generation/withdrawal is according to the given schedule, the third component of ABT is zero. In case of over-drawal (withdrawal in excess of schedule), beneficiary has to pay UI charge according to the frequency dependent rate specified.

Beside promoting competition, efficiency and economy and leading to more economically viable power scenario, ABT has been able to pave way for high quality power with more reliability and availability through enhanced grid discipline. 
- By giving incentives for enhancing the output capability of power plants, it enables more consumer load to be met during peak hours.

- By separating fixed charges based on availability from variable charges, backing down during off peak hours no longer results in financial loss to generating stations. Therefore, earlier incentive for not backing down and raising system frequency during off-peak hours no longer exists.

- By charging separately for unscheduled interchanges, the problem of over-drawal during peak load condition, resulting in lowering of frequency, has been controlled. UI rate is high during the low frequency condition, which discourages the over-drawal of power.

Apart from these intended benefits, the ABT mechanism has provided a vast scope of unscheduled interchange of as and when available surplus energy in the grid.

\section{Modeling of Frequency-UI Price Block}

The shape of UI price vs. frequency curve has been a subject of much debate among the sector participants. Regular modifications have been done in the shape of UI curve since it was introduced in 2000. The modifications have been ordered by Central Electricity Regulatory Commission (CERC), so as to meet the stated objectives of ABT mechanism. Initially, the frequency range in which UI prices vary was set between 49.0 and $50.5 \mathrm{~Hz}$ (CERC, 2000). In 2009, CERC has come up latest regulations (CERC, 2009) which set the frequency range between 49.2 and $50.3 \mathrm{~Hz}$. UI Price varies inversely with frequency. In the original regulations, the minimum price was zero INR/kWh at $50.5 \mathrm{~Hz}$ and maximum price limit was $4.80 \mathrm{INR} / \mathrm{kWh}$ at 49.0 Hz. In the 2009 regulations, minimum price is zero INR/kWh at $50.3 \mathrm{~Hz}$ and maximum price is $7.35 \mathrm{INR} / \mathrm{kWh}$ at $49.2 \mathrm{~Hz}$. This curve is shown in Figure 1. The maximum price cap is set by CERC to accommodate the highest price generation in the system. Now, CERC has adopted a process whereby the max UI price cap is to be reviewed six monthly. Additionally, there are kinks (or dual slopes) in the UI curve. In the March 2009 UI curve shown in Figure 1, the price varies from $7.35 \mathrm{INR} / \mathrm{kWh}$ at $49.2 \mathrm{~Hz}$ to $4.80 \mathrm{INR} / \mathrm{kWh}$ at $49.5 \mathrm{~Hz}$ in steps of $0.17 \mathrm{INR} / \mathrm{kWh}$ per $0.02 \mathrm{~Hz}$ and from $4.80 \mathrm{INR} / \mathrm{kWh}$ at $49.2 \mathrm{~Hz}$ to zero INR/kWh at $50.3 \mathrm{~Hz}$, in steps of $0.12 \mathrm{INR} / \mathrm{kWh}$ per $0.02 \mathrm{~Hz}$.

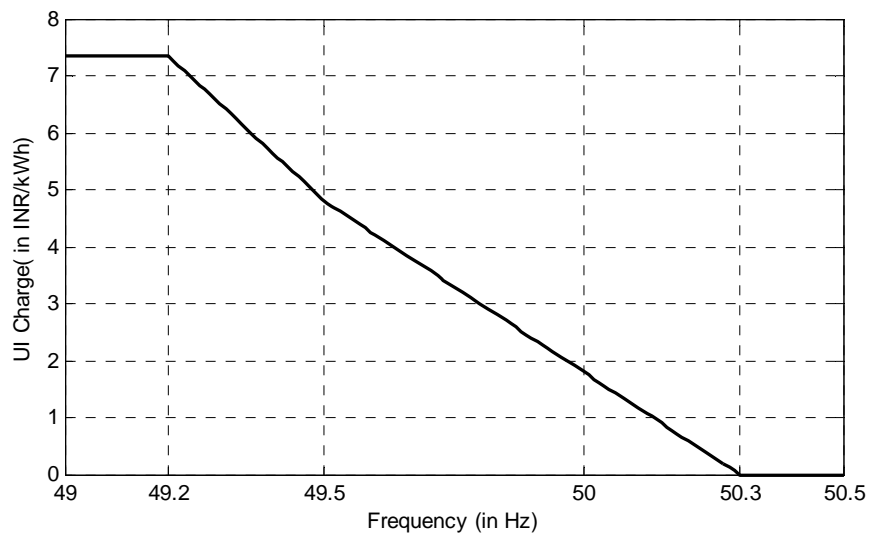

Figure 1. UI Price vs. Frequency Chart (March, 2009)

We use a frequency to price conversion block for modeling the price responsive generation in this paper. Although the UI price varies in discreet steps of $0.02 \mathrm{~Hz}$, we assume continuous variation of frequency for this work. The block is implemented in SIMULINK using embedded MATLAB function block. The code for the block is given in Figure 2.

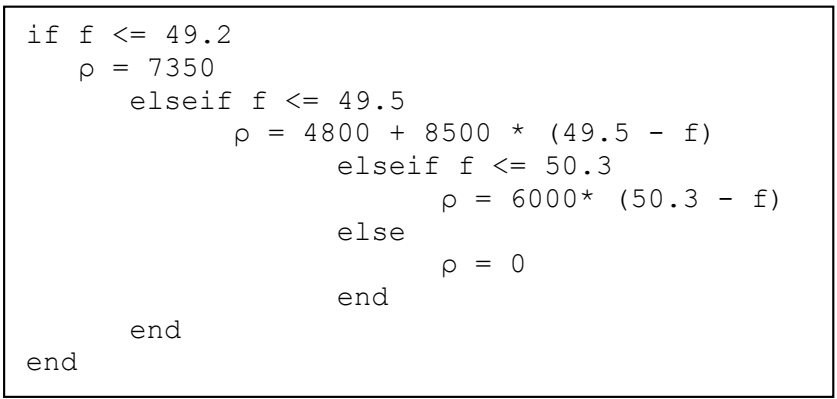

Figure 2. Frequency to Price conversion block 


\section{Proposed Generation Control Model}

As a result of successful implementation of UI mechanism in Indian electricity sector, a UI price signal is always available in real-time. This price signal fluctuates with grid frequency and can easily be accessed by any participant (generator or load) connected to the grid. This section explains a price based generation control mechanism, which can be adopted by generators by utilizing the UI price signal.

Indian Electricity Grid Code (IEGC) stipulates a Free Governor Mode of Operation (FGMO) for all generation units connected to the regional grid. According to IEGC, the droop of the governors should be set between 3 to 6 percent (IEGC, 2006). The FGMO is a primary level control, which acts as a first line of defense against sudden frequency riselfall. With only FGMO acting, the system deviates from nominal frequency and generation units deviate from their respective schedules, in response to changes in load. Conventionally, a secondary level control (LFC or AGC) is recommended to bring frequency back to nominal value. Implementation of a successful secondary control mechanism is not possible in India under present circumstances, as there is a generation shortage. However, the UI mechanism of ABT itself is meant to provide a secondary level control. The generation units are expected to respond to the UI price signal in real-time. Although the wide fluctuations in frequency have been tamed through implementation of UI mechanism, the frequency profile is still not as smooth as desirable. The Generation units respond to the UI price signal manually, often resulting in a delayed response. This causes frequency to fluctuate rapidly. Sometimes, the generation units may not act or may act out of merit. This results in a higher UI price than expected.

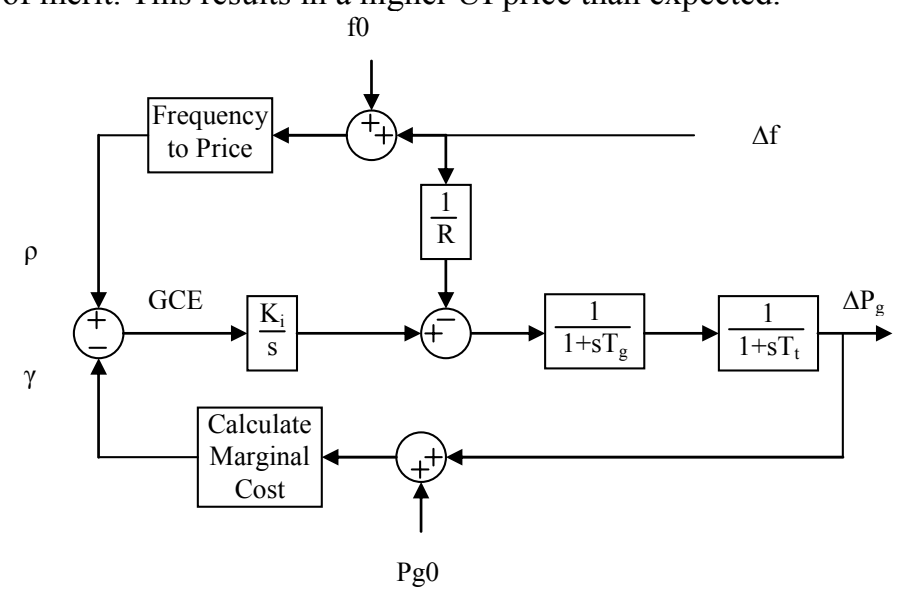

Figure 3. Price based automatic generation control

This section describes a PBAGC that will ensure that generators respond to the UI price automatically and in a desirable manner. The desirable properties of this controller are:

- It should ensure that frequency control is as smooth as possible

- It should ensure that UI price is minimum possible.

The basic principle of this control is illustrated in Figure 3. Each generator individually monitors the UI price $\rho$ and compares with its marginal cost $\gamma$. It derives an error signal, which is the difference of current UI price and its own marginal cost. This error signal, which can be termed as generation control error (GCE), is fed to an integral controller. A positive GCE indicates that the generator will profit by increasing generation level. A negative GCE indicates that Generator will profit by decreasing the generation level. Since under ABT, the payments received by generators for UI are separate from the payments for SI, the generators earn profit in both cases.

\section{Simulation Study and Results}

The control scheme described in the previous section is similar to one suggested by Tyagi and Srivastava (2004). This scheme has a shortcoming. It runs into problem due to fixed nature of UI curve. Under current regulations (CERC, 2009), UI price is pegged at $1800 \mathrm{INR} / \mathrm{MWh}$ at $50 \mathrm{~Hz}$ frequency. This means that if everyone (Generators and Loads) adhere to the schedule, the frequency should be $50 \mathrm{~Hz}$ and UI price $1800 \mathrm{INR} / \mathrm{MWh}$. However, at $1800 \mathrm{INR} / \mathrm{MWh}$ UI price some generators get an error signal causing them to deviate from their schedule. This may even cause the frequency to deviate from nominal value. This outcome is undesirable, as it results in UI among generators even when load is as per schedule.

To illustrate our point, we simulated an isolated area system having a capacity of $5000 \mathrm{MW}$ supplied by four generating stations. The relevant data of isolated area and generating stations is given in Table 1 and Table 2 respectively. All models are created using MATLAB/SIMULINK. Let us consider three scenarios: 
Table 1. Area Data

\begin{tabular}{|c|c|}
\hline Capacity & $5000 \mathrm{MW}$ \\
\hline $\mathrm{H}$ & $25000 \mathrm{MWs}$ \\
\hline $\mathrm{D}$ & $100 \mathrm{MW} / \mathrm{Hz}$ \\
\hline$f^{0}$ & $50 \mathrm{~Hz}$ \\
\hline
\end{tabular}

Table 2. Generator Data

\begin{tabular}{|c|c|c|c|c|c|}
\hline \multicolumn{2}{|c|}{} & Generator 1 & Generator 2 & Generator 3 & Generator 4 \\
\hline \multicolumn{2}{|c|}{ Capacity (MW) } & 1500 & 1500 & 1000 & 1000 \\
\hline \multirow{2}{*}{$\begin{array}{c}\text { Cost } \\
\text { Coefficients }\end{array}$} & $b_{i}(\mathrm{INR} / \mathrm{MWh})$ & 800 & 1000 & 1600 & 2000 \\
\cline { 2 - 6 } & $c_{i}\left(\mathrm{INR} / \mathrm{MWh}^{2}\right)$ & 0.3 & 0.3 & 0.4 & 0.4 \\
\hline
\end{tabular}

Table 3. Generation Schedule (in MW)

\begin{tabular}{|l|c|c|c|c|}
\hline & Generator 1 & Generator 2 & Generator 3 & Generator 4 \\
\hline Scenario 1 & 1500 & 1333.33 & 250 & 0 \\
\hline Scenario 2 & 1500 & 1500 & 83.33 & 0 \\
\hline Scenario 3 & 1500 & 1500 & 250 & 0 \\
\hline
\end{tabular}

Scenario 1: The generators are scheduled in merit order and load level results in system marginal cost of 1800 INR/MWh.

This scenario represents the only case in which price based generation control works successfully. The scheduled generation of this scenario is given in first row of Table 3. For this scenario, the generation is scheduled so that the overall system marginal cost is $1800 \mathrm{INR} / \mathrm{MWh}$. The load level does not change during the simulation. This means that none of the generators will get any error signal. The outcome of simulation is shown in Figure 4. It is observed that there is no impact on either frequency/UI price or scheduled generation.

Scenario 2: Load level results in system marginal cost of $1800 \mathrm{INR} / \mathrm{MWh}$ but generators are not scheduled in merit order.

The scheduled generation for this scenario is given in the second row of Table 3 . In this case, the generation is not scheduled as per merit order. Even if the load level is kept same, the generators scheduled out of merit will get error signal and will reschedule. The results of simulation are shown in Figure 5. Although the frequency and UI price are restored, the generation of second and third generator is rescheduled.

Scenario 3: Load level results in a system marginal cost higher that $1800 \mathrm{INR} / \mathrm{MWh}$.

The scheduled generation for this scenario is given in third row of Table 3. Until now, the load has been kept at a level so that the system marginal cost comes out to be $1800 \mathrm{INR} / \mathrm{MWh}$. However, this would rarely be the case. The results of simulation are shown in Figure 6. The outcome of simulation shows that even when there is no load change, neither the nominal frequency / UI price nor the scheduled generation can be maintained.
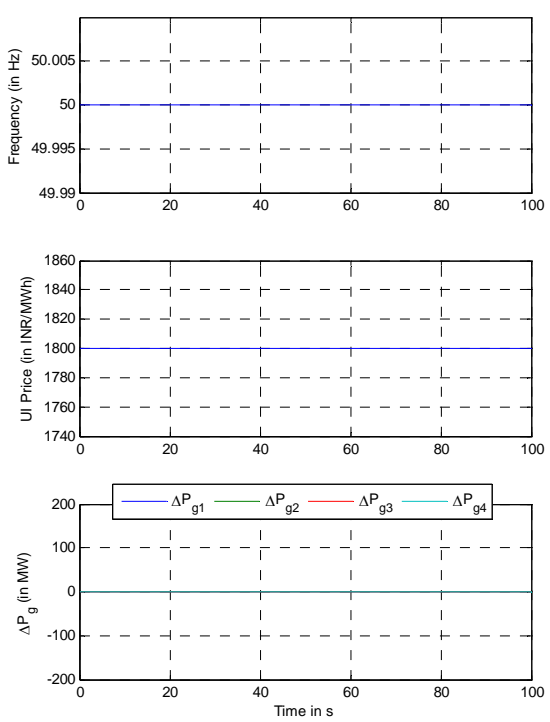

Figure 4. Scenario 1
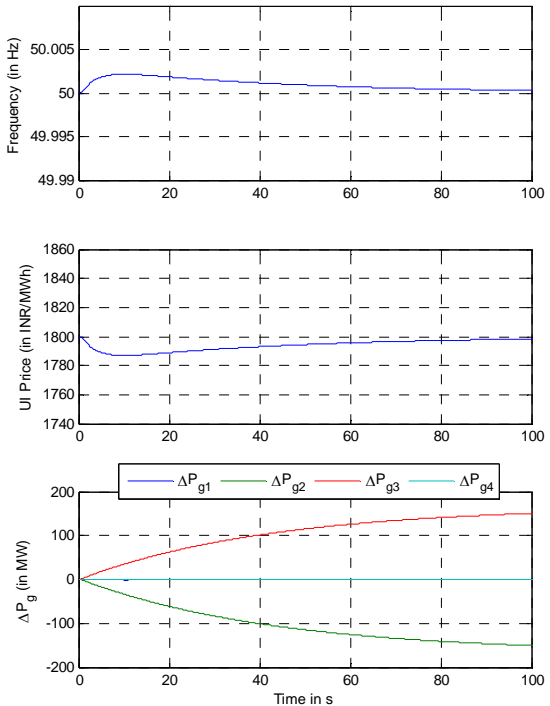

Figure 5. Scenario 2
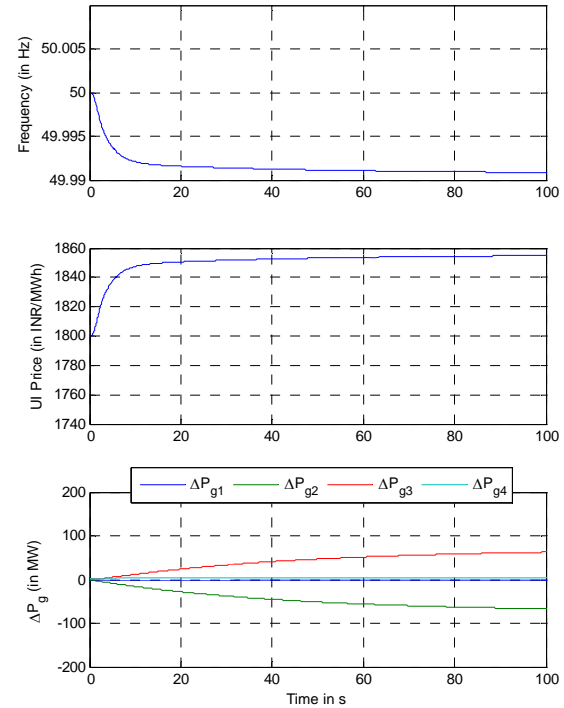

Figure 6. Scenario 3 
Therefore, there is a need to improve the proposed control mechanism so that no action is taken by generators if all the loads and other generators stick to their respective schedules. Instead of computing GCE for each generator in a simple manner as shown in Figure 3, a new algorithm for computing GCE is proposed. Flowchart of modified control scheme is shown in Figure 7. This control scheme ensures that schedules are maintained even if there is no load change, and suitable action is taken if there is a load change. The basic approach of the proposed control scheme is that it deals with generators with marginal cost higher than 1800 INR/MWh, and those with marginal cost less than equal to $1800 \mathrm{INR} / \mathrm{MWh}$ in a different manner. For the generators whose marginal cost is greater than $1800 \mathrm{INR} / \mathrm{MWh}$, the next step is to see if UI price is higher than its marginal cost, than GCE is set at $\rho$ minus $\gamma$. In case UI price is less than $1800 \mathrm{INR} / \mathrm{MWh}, \mathrm{GCE}$ is set at $\rho-1800$ and in case UI price is in between the marginal cost of generator and 1800, GCE is set at zero. This ensures that GCE would be positive if UI price is greater than the marginal cost of generator and negative if UI price is less than $1800 \mathrm{INR} / \mathrm{MWh}$ and would be zero otherwise. Similarly, for generators having marginal cost less than $1800 \mathrm{INR} / \mathrm{MWh}$, GCE would be positive if UI price is greater than $1800 \mathrm{INR} / \mathrm{MWh}$ and negative if UI price is less than the marginal cost of generator and would be zero otherwise.

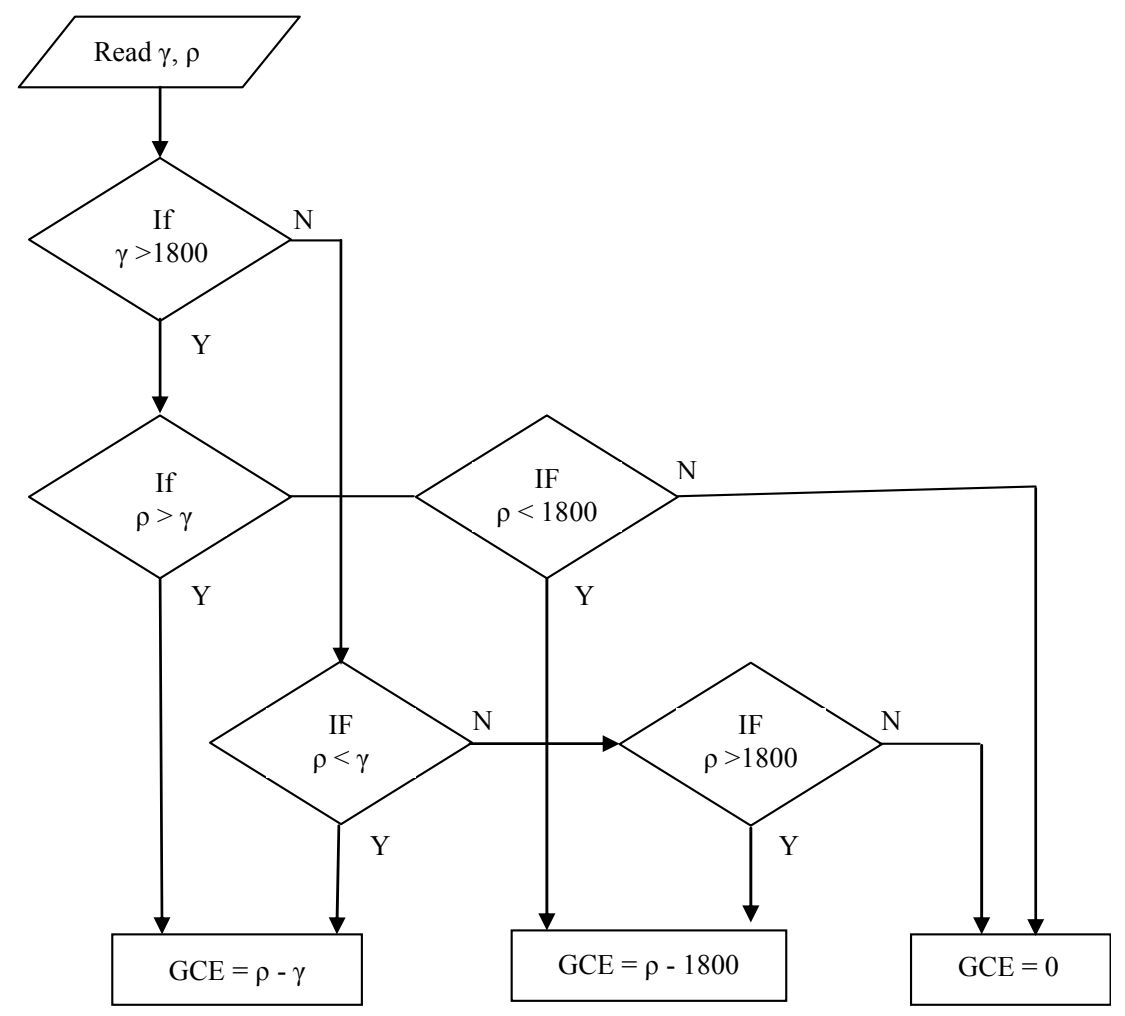

Figure 7. Flowchart for calculating GCE

To verify the outcome of proposed control, we apply this scheme to all three scenarios described before. The generation schedule or frequency does not deviate in any of the three cases. The result of application of proposed control on third scenario is given in Figure 8. We further test the operation of proposed control in Scenario 3 under application of a step load change of $100 \mathrm{MW}$. The results are shown in Figure 9. In this case, Generator 1 and 2 are loaded to their maximum capacity, hence cannot absorb any load increase. Only Generator 3 loaded at $250 \mathrm{MW}$ and Generator 4 loaded at zero MW have a capacity to increase generation. As soon as load increase is applied, the frequency falls and consequently UI price rises, reaching around $2400 \mathrm{INR} / \mathrm{MWh}$. Since, the current marginal cost of Generator 3 is $1800 \mathrm{INR} / \mathrm{MWh}$ and that of Generator 4 is $2000 \mathrm{INR} / \mathrm{MWh}$, both generators get a positive GCE. Generator 3 and 4 take corrective action and UI price finally settles at $1875 \mathrm{INR} / \mathrm{MWh}$. At this UI price, Generator 3 should absorb all the load change and Generator 4 should get a GCE equal to zero. We observe that Generator 3 has not completely absorbed the load increment. Out of $100 \mathrm{MW}$, around five MW is taken by Generator 4. This small generation by Generator 4 is the result of primary action (FGMO) of Generator 4. The final value of UI price is 1875 INR/MWh, which corresponds to 49.9875 $\mathrm{Hz}$. The frequency settles at a value less than nominal, hence some generation of Generators 3 and 4 will be due to their FGMO or primary control action. Ultimately, we can conclude that proposed price based control, unlike a conventional secondary, may not restore frequency to nominal value. However, if compared to only FGMO, it reduces the frequency error considerably and minimizes the UIs taking place in the system. 

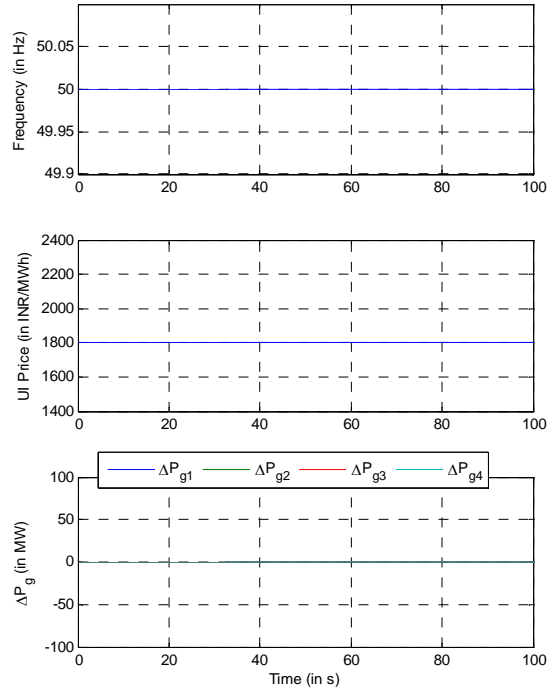

Figure 8. Scenario 3
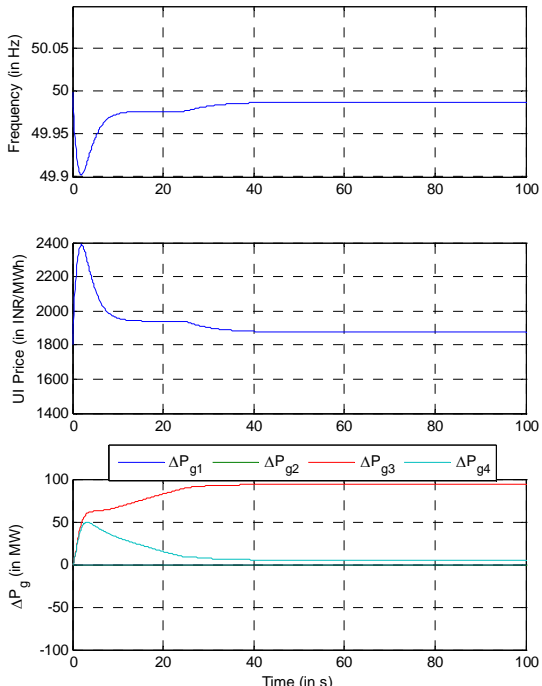

Figure 9. Scenario 3 (+100 MW step load change)
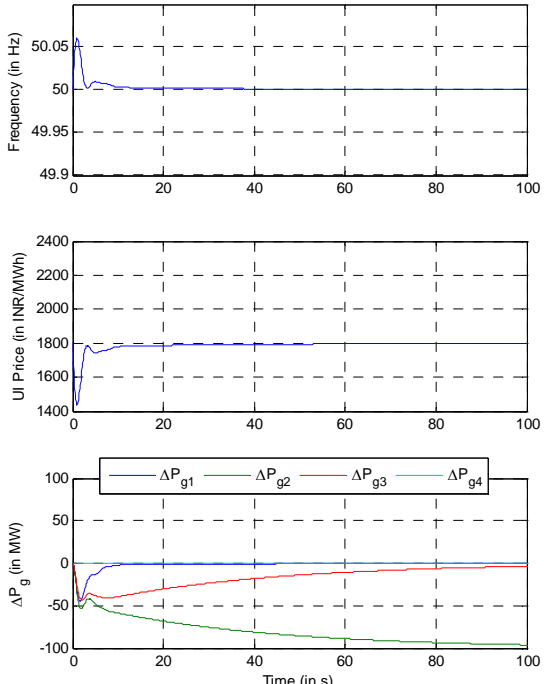

Figure 10. Scenario $3(-100 \mathrm{MW}$ step load change)

A step load change of $-100 \mathrm{MW}$ is applied to check the performance of the proposed control under load decrement. The results are shown in Figure 10. A rise in frequency is observed and consequently the UI price falls to around 1450 INR/MWh. Only Generators 1, 2, and 3 are capable of reducing their outputs. At scheduled load, marginal cost of Generators 1, 2, 3 are 1700, 1900 and $1800 \mathrm{INR} / \mathrm{MWh}$ respectively. All generators including Generator 1, whose marginal cost is less than $1800 \mathrm{INR} / \mathrm{MWh}$, get a negative GCE. As a result of corrective action taken by these generators, the UI price rises to $1800 \mathrm{INR} / \mathrm{MWh}$ and frequency is restored to $50 \mathrm{~Hz}$. Since the generators were loaded out of merit initially, there is sufficient capacity available with Generator 2 , who has the highest marginal cost, to absorb reduction of $100 \mathrm{MW}$. Had the generators been loaded in merit order, a load reduction of 100 MW would have certainly resulted in small frequency rise. We have seen that the proposed control scheme gives satisfactory results in terms of frequency control and UI reduction for a variety of operational conditions.

\section{Conclusions}

This paper discusses UI mechanism of ABT as a price based secondary control, which is manual in nature. It presents a price based automatic generation control that can be implemented in Indian system. It is shown that this control, if not suitably modified, will result in undesirable UIs. A modified controller is proposed which is able to deal with fixed nature of UI curve. The working of modified controller is verified through simulation of various scenarios and it is shown that it is able to avoid undesirable UIs. The successful operation of modified PBAGC is further tested by applying a step load increase and a step load decrease. The results of simulation show that the control is successful in bringing down the frequency deviation. The final frequency under this control may not settle to nominal value, but to a value equivalent to system marginal cost (on UI price vs. frequency curve) while serving the load.

Implementation of proposed control on all central and state generating stations will not only result in better control of frequency, but merit order dispatch of generation can also be ensured at the same time. The UI obligations of participants can be drastically reduced through this mechanism. In this paper, modified PBAGC is applied to an isolated area test system. In future, the impact of such mechanism on frequency, UIs and tie-line exchanges can be observed by taking multi-area systems.

\section{Nomenclature}

$f \quad$ Frequency $(\mathrm{Hz})$

$\rho \quad$ Unscheduled interchange price (INR/MWh)

$\gamma \quad$ Marginal cost (INR/MWh)

$b_{i} \quad$ First order cost coefficient (INR/MWh)

$c_{i} \quad$ Second order cost coefficient (INR/MWh ${ }^{2}$ )

$\mathrm{H} \quad$ Inertia constant of isolated area (MW-s)

D Load damping of isolated area $(\mathrm{MW} / \mathrm{Hz})$

ABT Availability Based Tariff 
AGC Automatic Generation Control

CERC Central Electricity Regulatory Commission

CGS Central Generating Station

FGMO Free Governor Mode of Operation

GCE Generation Control Error

IEGC Indian Electricity Grid Code

LFC Load Frequency Control

PBAGC Price Based Automatic Generation Control

RLDC Regional Load Dispatch Center

SEB State Electricity Board

UI Unscheduled Interchange

\section{References}

Bhushan B., Roy A. and Pentayya P., 2004. The Indian Medicine. Proc. of IEEE PES General Meeting, Denver, USA. Vol. 2, pp. 2236-2239.

Bhushan B., 2005. ABC of ABT: A primer on availability tariff. Available online: http://www.nrldc.org/docs/abc abt.pdf.

Central Electricity Authority, 2009. Load Generation Balance Report 2009-10. CEA, New Delhi, India. Available online: http://cea.nic.in/god/gmd/lgbr_report.pdf

Central Electricity Regulatory Commission, 2000. ABT Order. CERC, New Delhi, India. Available online: http://www.cercind.gov.in/orders/2-1999GOIABT040100.pdf

Central Electricity Regulatory Commission, 2009. Unscheduled interchange charges and related matters regulation, 2009. CERC, New Delhi, India. Available online: http://www.cerc.gov.in.

Gupta A.P. and Sathaye J., 2009. Electrifying India. IEEE Power and Energy Magazine. Vol. 7, No. 5, pp. 53-61.

Indian Electricity Grid Code, 2006. Available online: http://cercind.gov.in/Regulations/Indian-Electricity-Grid-Code-2006.pdf.

Roy A., Khaparde S.A., Pentayya P. and Pushpa S., 2005. Operating Strategies for Generation Deficient Power System. Proc. IEEE PES General Meeting, San Francisco, USA. Vol. 3, pp. 2738-2745.

The Gazette of India, Extraordinary, 2003. The Electricity Act, 2003 Part II Section 3 Sub-section (ii) June 10, 2003. Ministry of Power, Government of India, New Delhi., Available online: http://www.powermin.nic.in/acts_notification/electricity_act2003 /pdf/The\%20Electricity\%20Act_2003.pdf

Tyagi B. and Srivastava S.C., 2004. A mathematical framework for frequency linked availability based tariff mechanism in India. National Power Systems Conference, IIT Madras, Chennai, India, Vol. 1, pp. 516-521.

Yadav R.G., Roy A., Khaparde S.A., Pentayya P., 2005. India's fast-growing power sector. IEEE Power and Energy Magazine. Vol. 3, No. 4, pp. 39-48.

\section{Biographical notes}

Saurabh Chanana received bachelors and master degree in technology from National Institute of Technology Kurukshetra, India in 1996 and 2002 , respectively. Currently, he is assistant professor in the Electrical Engineering, National Institute of Technology Kurukshetra, India. His research interests include power system restructuring, power system optimization \& control, demand side management and FACTS applications. He is a life member of ISTE (India) and a member of IEEE.

\footnotetext{
Ashwani Kumar did his bachelors of technology in Electrical Engineering from G. B. Pant University of Agriculture and Technology, Pant Nagar in 1988 and master's degree from Punjab University Chandigarh in 1994 in honors. He obtained his Ph.D. from IIT Kanpur, India in Oct. 2003. He has his interests in power system restructuring, FACTS applications, power systems dynamics, distributed generation, demand side management, and price forecasting. He is member of IEEE, life member of Indian Society of Technical Education, (ISTE), and life member of Institution of Engineers (IEI) India. Presently, he is working as associate professor in the Department of Electrical Engineering, National Institute of Technology, Kurukshetra, India.
}

Received December 2009

Accepted February 2010

Final acceptance in revised form March 2010 